\title{
Hypnoparenting as A Way for Parents to Build Positive Personality in Children
}

\author{
Arina Firdaningrum, Afrida Muarifa, Laelatus Soimah
}

Universitas Sebelas Maret

arinafirdaningrum@student.uns.ac.id

\section{Article History}

accepted 24/09/2019

approved 01/10/2019

published 01/12/2019

\begin{abstract}
The development of civilization in this century is marked by many behaviors that show a negative personality. The formation of a child's personality needs to start early. Parents are an initial basis of life for every human being. So the family especially parents have the most important role to build a positive personality in children. The purpose of this paper is to explain the concepts, ways, and the right time to do Hypnoparenting. Hypnoparenting is a method of parenting, educating, and caring for children which is done by the method of hypnosis. How to do Hypnoparenting is by suggesting children with sentences that can make children confident and with words that are positive. There are some of the best times to consider in conducting Hypnoparenting method. The method used in this research is literature study. Sources taken are based on scientific journals and research reports relating to the problem.
\end{abstract}

Keywords: personality, parenting, hypnoparenting.

\section{Abstrak}

Perkembangan peradaban pada abad ini banyak diwarnai perilaku yang menunjukan kepribadian yang negatif. Pembentukan kepribadian anak perlu dimulai sejak dini. Orang tua merupakan sebuah basis awal kehidupan bagi setiap manusia. Maka keluarga terutama orang tua memiliki peran yang paling penting untuk membangun kepribadian positif pada anak. Tujuan dari penulisan ini adalah untuk menjelaskan tentang konsep, cara, dan waktu yang tepat untuk melakukan Hypnoparenting. Hypnoparenting merupakan metode parenting, mendidik, dan pola asuh anak yang dilakukan dengan metode hypnosis. Cara melakukan Hypnoparenting yaitu dengan mensugesti anak dengan kalimat-kalimat yang mampu membuat anak percaya diri dan dengan kata-kata yang bernilai positif. Terdapat beberapa waktu terbaik yang perlu diperhatikan dalam melakukan metode Hypnoparenting. Metode yang digunakan dalam penelitian ini adalah studi kepustakaan. Sumber yang diambil yaitu berdasarkan jurnal ilmiah serta laporan penelitian yang berkaitan dengan permasalahan.

Kata kunci: Kepribadian, Parenting, Hypnoparenting

Social, Humanities, and Education Studies (SHEs): Conference Series https://jurnal.uns.ac.id/shes

p-ISSN 2620-9284

e-ISSN 2620-9292 


\section{PENDAHULUAN}

Permasalahan sering kali muncul dalam proses pertumbuhan dan perkembangan keprbadian. Permasalahan kepribadian pada diri individu dapat menimbulkan sikap amoral yang menunjukan rendahnya moralitas, contohnya pemerkosaan, korupsi, kriminalitas, kekerasan, dan masih banyak lagi. Perkembangan pembentukan kepribadian manusia dipengaruhi oleh berbagai faktor, oleh karena itu kepribadian bukan merupakan hal yang mutlak. Kepribadian dapat dibentuk sesuai dengan kepribadian yang normal dan mudah menyesuaikan diri (adaptif).

Menurut Chairilsyah (2012), Dinamika kepribadian meruapakan sifat-sifat dinamis yang dimilki oleh suatu kepribadian tertentu, dinamika memilki arti "gerak" oleh karena itu kepribadian bukanlah sesuatu yang statis. Pada masa kanak-kanak, anak-anak memiliki pribadi yang belum matang sehingga dinamika kepribadian ini dapat dengan mudah berkembang secara pesat pada diri anak-anak. Berikut ini merupakan definisi kepribaian menurut para ahli, antara lain:

1. George Kelly, menurutnya kepribadian merupakan cara-cara unik yang dilakukan individu untuk menyampaikan pengalaman-pengalaman hidup yang dialaminya.

2. Gordon Allport, ia mengartian bahwa kepribadian merupakan sebuah organisasi dinamis dari psikofisik seorang individu yang bertujuan untuk menentukan tingkah laku dank ke-khas-an individu dalam berfikir.

3. Bowner,ia berpendapat bahwa kepribadian merupakan bentuk tingkah laku sosial, ketakutan, dorongan dan keinginan, tingkah laku seseorang, pendapat, dan juga sikap atau perilaku seseorang. Menurutnya pula tidak semua perilaku bersifat tampak, ada pula perilaku yang bersifat tidak tampak.

Dari definisi-definisi kepribadian menurut ahli tersebut dapat diambil kesimpiulan bahwa kepribadian merupakan cara berbeda atau unik yang dilakukan oleh setiap individu dalam proses interaksi dengan lingkungannya yang menggunakan kecerdasan kognitif, emosional, dorongan, juga kebutuhan sosial yang ditunjukkan dengan suatu perilaku tertentu, pola-pola perilaku ini bisa tampak maupun tidak tampak sesuai dengan kebutuhan.

Dalam membangun kepribadian seorang anak,peran lingkungan keluarga terutama orang tua sanagatlah penting. Di lingkungan masyarakat, keluarga merupakan satuan kelompok sosial terkecil, dimana keluarga merupakan merupakan orang yang pertama kali dikenal oleh anak sejak lahir. Keluarga memberikan pendidikan serta bimbingan pertama kali bagi anak yang dimana pola bimbingan tersebut akan terus berjalan sepanjang masa. Interaksi-interaksi yang terjadi dalam keluarga (komunikasi dan pola tingkah laku) menjadi cerminan yang berfungsi untuk membentuk kepribadian anak.

Gilbert Highes dalam Fatmawati (2016) berpendapat bahwa keluarga berperan besar dalam pembentukkan kebiasaan anak. Sejak anak membuka mata di pagi hari hingga terlelap dimalam hari, keluarga selalu memberikan pengaruh dan pendidikan dari ligkungan keluarga. Keluarga berperan sebagai suatu sistem sosial yang bertugas untuk membentuk karakter serta moral seorang anak. Keluarga bukan hanya suatu tempat berkumpulnya ayah, ibu, dan anak, tetapi sesungguhnya keuluarga memilki peran yang lebih dari itu. Keluarga berperan sebagai penyedia tempat yang ternyaman bagi anak. Segala sesuatu perkembangan kepribadian anak dimulai di lingkungan keluarga. Keluarga diumpamakan sebagai payung kehidupan bagi seorang anak. Kemampuan berpendapat, bersosiaisasi, mengaktualisasikan diri, hingga perilaku yang menyimpang tumbuh pertama kali di lingkungan keluarga.

Menurut Agustin, dkk (2015) yang dikutip dari KIngslet Davis dalam Murdianto mengemukakan bahwa fungsi dari keluarga ialah sebagai berikut:

1. Reproduction, merupakan cara yang dilakukan agar menghasilkan generasigenerasi baru yang bertujuan untuk mengganti apa yang telah hilang atau habis untuk kelestarian sistem sosial. 
2. Maintenance, merupakan pengasuhan yang dilakukan oleh orang tua kepada anak hingga sang anak mampu berdiri sendiri.

3. Placement, merupakan pembagian posisi sosial untuk anggota keluarganya baik sebagai kepala keluarga, anggota keluarga, maupun posisi-posisi lain dalam keluarga.

4. Socialization, merupakan pewarisan nilai-nilai sosial oleh orang tua kepada anak yang berlaku di masyarakat sehingga sang anak dapat diterima oleh enggota masyarakat lain dengan wajar.

5. Economic, merupakan fungsi keuarga untuk memenuhi kebutuhan baik barang maupun jasa dengan cara produksi, distribusi, dan konsumsi dengan pelaku antar anggota keluarga.

6. Care of the ages, merupakan perawatan kesehatan yang diberikan kepada anggota keluarga yang telah berusia lanjut.

7. Political center, merupakan pemberian posisi politik bagi anggota keluarga di lingkungan masyarakat yang ia tinggali.

8. Physical protection, merupakan perlindungan fisik yang diberikan kepada anggota keluarga berupa sandang, pangan, dan papan.

Menurut Pratomo (2012) dalam Maghfiroh (2015), hypnoparenting merupakan salah satu metode yang banyak digunakan oleh keluarga yang berfungsi untuk membentuk kepribadian anak. Hypnoparenting sendiri berasal dari dua suku kata yairtu hypnosis dan parenting. Hypnosis memilki arti penurunan kesadaran, sedangkan parenting berarti segala bentuk cara yang dilakukan orang tua untuk mendidik dan membesarkan buah hatinya. Tidak hanya digunakan dalam terapi penyembuhan penyakit fisik dan mental, metode hypnosis ini juga dapat dimanfaatkan dalam berbagai bidang antara lain di bidang hukum, hiburan, kriminalitas, bahkan dapat pula digunakan dalam bidang manajemen pemasaran.

\section{Konsep Hypnoparenting}

\section{HASIL DAN PEMBAHASAN}

Menurut Ardianti (2015), hypnosis bukan merupakan hal yang tabu dan berkaitan dengan hal-hal yang bersifat magic. Hypnosis ada di setiap situasi dan aktivitas kehidupan, termasuk ketika proses belajar mengajar. Ketika seseorang dalam kondisi hypnosis maka akan dengan mudah menerima saran dari orang lain. Kondisi hypnosis berbeda dengan keadaan tidur. Ketika seseorang sedang tidur ia tidak sadar akan kondisi disekitarnyanya, sementara pada keadaan hypnosis seseorang akan tetap sadar akan keadaan di sekitarnya. Pada kondisi ini orang tersebut hanya berpindah kesadaran dari pikiiran sadar ke pikiran alam bawah sadar.

Pengertian parenting adalah tugas orang tua untuk mengasuh dan mendidik anaknya sesuai dengan karakter yang dimiliki anak agar menjadi pribadi yang kreatif dan positif. Orang tua harus bijak dan berhati-hati dalam mendidik anak. Pola pengasuhan anak perlu dipelajari oleh setiap orang tua, sehingga mereka dapat membesarkan anak dengan baik.

Bianda Nadia (2010:120) dalam Silawati dan Yanti (2015) mengatakan hypnoparenting berasal dari kata hypnosis dan parenting (mendidik anak). Hypnoparenting merupakan salah satu aplikasi hipnosis untuk tujuan merawat dan mendidik anak (parenting). Hypnoparenting dilakukan dengan menyugesti anak dengan kalimat-kalimat yang mampu membuat anak percaya diri dan dengan kata kata yang bernilai positif .

Secara lebih luas, Navis (2013: 152) dalam Silawati dan Yanti (2015) menyatakan bahwa hypnoparenting adalah metode parenting, mendidik, dan pola asuh anak yang dilakukan dengan metode hipnosis, yaitu dengan memanfaatkan penurunan frekuensi gelombang otak anak untuk diberi sugesti positif. Harapannya, dengan sudut, 
keyakinan, dan pembahasan baru, kita dapat mengubah perilaku negatif anak menjadi perilaku yang positif.

Berdasarkan uraian di atas, dapat disimpulkan bahwa hypnoparenting adalah cara yang dilakukan orang tua untuk mendidik anak dengan cara memberikan sugesti positif pada anak, sehingga anak akan menyimpan sugesti tersebut dalam pikiran bawah sadar.

Hypnoparenting bekerja langsung pada alam bawah sadar anak. Orang tua dapat menerapkan pola pengasuhan, termasuk membangun sikap disiplin pada anak dengan mudah tanpa paksaan. Teknik pengasuhan ini sangat sistematis dan sederhana. Penerapannya mudah, asalkan paham teknik yang tepat dan benar. Hypnoparenting sangatlah efektif, asalkan orang tua menyediakan lingkungan yang kondusif bagi tumbuhnya program yang disugestikan. Untuk mengukur keberhasilan teknik ini dapat langsung tampak dari pola perilaku yang berubah sesuai dengan yang disugestikan.

\section{Cara-Cara Hypnoparenting}

Menurut Navis (2013) dalam Maghfiroh (2015), terdapat banyak pilihan cara untuk melakukan hypnoparenting pada anak yaitu:

a. Anak dalam Kondisi Mood Positif

Kondisikan anak dalam keadaan yang optimal dan siap melakukan hypnoparenting.

b. Membangun keakraban sebelum melakukan hypnoparenting

Ciptakan suasana keakraban antara orang tua dengan anak sebelum memulai hypnosis.

c. Mencari saat tepat untuk melakukan induksi atau afirmasi

Saat anak sudah dalam keadaan tenang, anak sudah terbuka dan akrab dengan orang tua.

d. Menggunakan alat bantu saat menginduksi atau memberikan afirmasi

Media yang paling tepat adalah media yang sangat dekat dengan anak, dapat menggunakan berbagai benda-benda di sekitar kita atau mainan yang disukai anak.

e. Melakukan kontak fisik secara kontinu

Kesedian orang tua untuk melakukan kontakfisik dengan anak, sehingga anak dapat melihat dan merasakan sendiri saat terbuka dengan orang tua jika dalam keseharian sering terjadi kontak fisik.

f. Memasukkan sugesti positif pada anak

Puncak dari proses hypnoparenting ketika memasukkan sugesti positif (afirmasi) pada pikiran bawah sadar anak. Sugesti yang ditanamkan orang tua diharapkan dapat tertanam pada pikiran bawah sadar anak.

g. Melakukan pengulangan secara konsisten

Melakukan pengulangan merupakan cara ampuh dan efektif untuk menanamkan sugesti positif dengan tujuan memprogram pikiran bawah sadar anak dengan program yang berkualitas.

\section{Waktu Efektif Dalam Melakukan Hypnoparenting}

Menurut Silawati dan Yanti (2015), ada beberapa waktu-waktu efektif yang bisa digunakan agar sugesti yang orang tua tanamkan dapat menancap dan menetap pada anak, yaitu :

a. Saat mengajak anak berdoa

Ketika berdoa, suasana tenang dan suara lirih sehingga tercipta ketenangan dan anak pun mudah dihypnosis.

b. Saat anak bermain

Saat bermain, anak biasanya terfokus pada permainannya. Kondisi ini bisa orang tua gunakan untuk menanamkan sugesti-sugesti positif. 
c. Saat sambil menggambar

Menggambar adalah media yang bisa digunakan untuk menghipnosis anak. Gunakanlah gambar sebagai awal dalam memasukn sugesti.

d. Saat sebelum tidur

Sebelum tidur merupakan waktu terbaik untuk menghipnosis anak. Anak berada dalam kondisi yang sangat rileks, tenang, dan otaknya berada dalam gelombang alpha atau theta sehingga RAS (Reticular Analisys System) terbuka lebar dan sugesti lebih mudah ditanamkan.

e. Saat sebelum bangun

Kondisi ini serupa dengan kondisi anak ketika tertidur pulas. Ketika pagi hari ia mulai terbangun, menggerakgerakkan tubuhnya, dan ada gerakan bola mata. Dibalik matanya yang masih terpejam, masukkan sugesti-sugesti positif.

f. Saat anak makan

Ketika anak sedang makan dalam keadaan yang relaks. Selain menikmati rasa dari makanan itu, ia juga menikmati suasana di sekelilingnya. Saat inilah orang tua bisa memberikan sugesti positif dalam pikirannya.

g. Saat mendiamkan anak menangis

Ketika tangisan anak mulai mereda, ia justru sedang menciptakan ketenangan dalam dirinya sendiri. Sambil menenangkan perasaan dan pikirannya, orang tua dapat menghipnosis anak secara perlahan.

h. Saat menggendong dalam bentuk buaian

Cara ini sangat efektif digunakan, karena anak berada dalam kondisi yang sangat tenang. Pikiran dan perasaannya juga berada pada tingkat yang rendah. Kondisi ini serupa dengan keadaan ketika ia hendak tidur.

i. Melalui nyanyian

Ada banyak nyanyian yang bisa digunakan untuk menghipnosis anak. Nyanyian dengan alunan nadayang lembut dan pelan bisa membuat anak terhipnosis dengan mudah.

j. Melalui dongeng

Mendongeng dapat dijadikan sebagai metode hypnosis yang efektif. Anak akan duduk diam dan menyimak dongeng yang dibacakan oleh orang tuanya. Pilihlah dongeng yang dapat memotivasi anak.

k. Saat belajar

Ketika anak sedang fokus pada suatu hal, ia akan lebih mudah menerima sugesti dari luar. Ucapkan sugesti dengan suara yang lembut dan nada yang rendah.

Keberhasilan orang tua dalam menanamkan nilai-nilai positif menggunakan metode ini tergantung dengan pola asuh yang diterapkan orang tua kepada anaknya. Karakter itu sama dengan akhlak dalam pandangan Islam yaitu kepribadian. Kepribadian terdiri dari tiga komponen yaitu pengetahuan, sikap dan perilaku. Yang dimaksud dengan kepribadian yang utuh adalah ketika ilmu diikuti dengan sikap dan juga perilaku. Karena pentingnya pendidikan karakter bagi anak maka orang tua harus bersungguh-sungguh dalam mendidik anaknya agar menjadi penerus bangsa yang berkarakter positif.

\section{SIMPULAN}

Pembentukan kepribadian dipengaruhi oleh dua faktor, yaitu internal dan eksternal. Faktor internal yaitu faktor yang berasal dari dalam diri seorang individu, sedangkan faktor eksternal yaitu faktor yang berasal dari lingkungan di sekitar individu. Proses pembentukan kepribadian seseorang dapat dibentuk oleh orang tua melalui metode hypnoparenting. Hypnoparenting adalah metode yang dilakukan dengan cara mensugesti anak dengan hal-hal yang positif. Waktu yang tepat untuk memberikan hypnoparenting pada anak adalah waktu ketika berdoa, bermain, menggambar, sebelum tidur, sebelum bangun, waktu ketika mereka makan, saat mendiamkan anak 
menangis, saat menggendong anak, melalui nyanyian, melalui dongeng dan ketika mereka sedang belajar. Dengan adanya metode hypnoterapi diharapkan dapat menjadi acuan orang tua dalam membentuk kepribadian positif pada anak.

\section{DAFTAR PUSTAKA}

Agustin, D. S. Y. Dkk. (2015). Peran Keluarga Sangat Penting dalam Pendidikan Mental, Karakter Anak serta Budi Pekerti Anak. Jurnal Sosial Humaniora, Vol 8 No.1, Juni 2015. Diakses dari: https://www.researchgate.net/publication/316925595 Peran Keluarga Sangat P enting dalam Pendidikan Mental Karakter Anak serta Budi Pekerti Anak. Pada tanggal 12 September 2019.

Ardianti. I. (2015). Konsep Hypnoparenting dan Relevansinya Dengan Pendidikan Karakter Anak. Program Studi Madrasah Ibtidaiyah Sekolah Tinggi Agama Islam Negeri (STAIN): Ponorogo. Diakses dari: http://etheses.iainponorogo.ac.id/749/1/BAB\%20I-V.pdf. Pada tanggal 30 September 2019.

Asterina, D. A. (2012). Hubungan Tipe kepribadian dengan perilaku asertif mahasiswa fakultas psikologi UIN Maulana Malik Ibrahim Malang. UIN MALANG. Diakses dari: http://etheses.uin-malang.ac.id/2260/1/08410139 Pendahuluan.pdf. Pada tanggal 9 September 2019.

Chairilsyah, D. (2012). Pembentukan Kepribadian Positif Anak Sejak Usia Dini. EDUCHILD. Vol. 01 No.1. Diakses dari: https://media.neliti.com/media/publications/22928-ID-pembentukan-kepribadianpositif-anak-sejak-usia-dini.pdf. Pada tanggal 9 September 2019.

Erlansi, S. M, dkk. (2016). Teknik Parenting Dan Pengasuhan Anak Studi Deskriptif Penerapan Teknik Parenting Di Rumah Parenting Yayasan Cahaya Insan Pratama Bandung. Vol.3. Diakses dari http://jurnal.unpad.ac.id/prosiding/article/download/13686/6524. $\quad$ Pada 10 September 2019.

Fatmawati. (2016). Peran Keluarga Terhadap Pembentukan Kepribadian Islam Bagi Remaja. Jurnal RISALAH, Vol. 27, No. 1, Juni 2016: 17-31. Diakses dari: https://media.neliti.com/media/publications/127797-ID-peran-keluarga-terhadappembentukan-kepr.pdf. Pada tanggal 10 September 2019.

Maghfiroh, A. (2015). Implementasi Hypnoparenting Dalam Pembentukan Kedisiplinan Anak Di Taman Kanak-Kanak Pangulir Budi I Kerangkulon, Kecamatan Wonosalam, Kabupaten Demak. Pendidikan Guru Pendidikan Anak Usia Dini Fakultas IImu Pendidikan Universitas Negeri Semarang: Semarang. Diakses dari: https://lib.unnes.ac.id/28814/1/1601411011.pdf. Pada tanggal 12 September 2019.

Susilawati dan Yanti, A. (2015). Pemanfaatan Hypnoparenting Dalam Menanamkan Karakter Anak Di Lembaga Konseling Dan Konsultasi Pekanbaru. Jurnal RISALAH, Vol. 26, No. 2, Juni 2015: 77-85. Diakses dari: https://media.neliti.com/media/publications/128015-ID-pemanfaatan-

hypnoparenting-dalam-menanam.pdf. Pada tanggal 10 September 2019. 